\title{
Enraizamento in vitro de mirtilo em condições fotoautotróficas
}

\author{
In vitro rooting of blueberry under photoautotrophic conditions
}

\author{
Cláudia Roberta Damiani ${ }^{{ }^{*}}$ Márcia Wulff Schuch ${ }^{\mathrm{I}}$
}

\section{RESUMO}

\begin{abstract}
O objetivo deste trabalho foi avaliar a eficiência do enraizamento fotoautotrófico de mirtilo (Vaccinium ashei Reade), cultivar 'Delite', comparando o efeito da luz natural (casa de vegetação) e da luz artificial (sala de crescimento) durante duas épocas do ano (verão e inverno), bem como o efeito de três concentrações de sacarose $\left(0 ; 15\right.$ e $\left.30 \mathrm{~g} \mathrm{~L}^{-1}\right)$ adicionadas ao meio de cultura e de diferentes tipos de vedação dos frascos de cultivo (alumínio, algodão e filme plástico). Após 60 dias de enraizamento in vitro em meio de cultura $W P M$, contendo $9 \mu M L^{-1}$ de $A I B$, observou-se que o enraizamento em meio de cultura livre de sacarose promoveu o aumento do número de raizes e da porcentagem de enraizamento e, quando associado ao fechamento dos frascos com algodão, favoreceu, também, o incremento do comprimento das raizes e da massa fresca total. Quanto ao ambiente de cultivo e às épocas do ano, concluiu-se que o enraizamento pode ser realizado com sucesso de forma fotoautotrófica e, durante o verão, independentemente do ambiente de cultivo, verifica-se um aumento do comprimento de raizes, da porcentagem de enraizamento e da massa fresca total.
\end{abstract}

Palavras-chave: Vaccinium ashei, vedação dos frascos, ambiente de cultivo, sacarose, luz natural, variação sazonal.

\section{ABSTRACT}

The aim of this research was to assess the photoautotrofic rooting efficiency of blueberry (Vaccinium ashei Reade), cultivar 'Delite' by comparing the effect between natural light (greenhouse) and artificial light (growth room) in two seasons (summer and winter), as well as the effect of different three sucrose concentrations $\left(0 ; 15\right.$ or $\left.30 \mathrm{~g} \mathrm{~L}^{-1}\right)$ added to the culture medium and different types of flasks closure (aluminum, cotton and plastic film). After 60 days of in vitro rooting on WPM medium culture containing $9 \mu M L^{-1} A I B$, rooting in freesucrose culture medium promoted an increased in the number of roots and rooting percentage; and, whether associated to cotton closed, there was an increase in length of roots and in the total fresh weight. Regarding environment growth and season, rooting could be successfully realized under photoautotrophic conditions. At summer, it was verified an increase in roots length, rooting percentage and total fresh weight independently of environment growth.

Key words: Vaccinium ashei, flasks closure, environment growth, sucrose, natural light, seasonal variation.

\section{INTRODUÇÃO}

Dentre as pequenas frutas, o mirtilo (Vaccinium spp) é uma fruta que tem se mostrado como uma alternativa viável e rentável para as pequenas propriedades devido à existência de um mercado bastante promissor. No Brasil, o quadro produtivo atual está estimado em cerca de 60 toneladas, concentrado nas cidades de Vacaria e Lavras, no Rio Grande do Sul, e Campos do Jordão, em São Paulo, totalizando uma área de 12 hectares em produção comercial (MADAIL \& SANTOS, 2004). No entanto, a área plantada ainda é pequena, principalmente devido à indisponibilidade, à qualidade e ao preço das mudas, situação decorrente da dificuldade de propagação da maioria das cultivares (TREVISAN et al., 2008).

\footnotetext{
ILaboratório de Micropropagação de Plantas Frutíferas, Departamento de Fitotecnia, Faculdade de Agronomia Eliseu Maciel (FAEM), Universidade Federal de Pelotas (UFPel), CP 354, 96010-900, Pelotas, RS, Brasil. E-mail: claudami2004@yahoo.com.br. *Autor para correspondência.
} 
A propagação vegetativa de mirtilo é realizada por meio de estaquia, micropropagação e rebentos. No Brasil, a produção comercial de mudas é realizada por meio de estaquia, mas os resultados práticos são insatisfatórios e bastante variáveis de acordo com a cultivar (FACHINELLO et al., 1995). A técnica de micropropagação vem sendo utilizada com resultados satisfatórios para a produção de mudas de mirtilo em escala comercial no Uruguai, em resposta à crescente demanda por parte de viveiristas e produtores (CASTILLO et al., 2004).

O uso da técnica de micropropagação, além da produção de grande quantidade de plantas em curto período de tempo, permite a obtenção de plantas livres de doenças e a propagação de espécies difíceis de serem multiplicadas por outros métodos. Outra vantagem do ponto de vista prático da micropropagação está relacionada à restauração da competência de enraizamento, resultado do rejuvenescimento obtido pelos sucessivos subcultivos e pelo uso de reguladores de crescimento (GRATTAPAGLIA \& MACHADO, 1998). Por outro lado, a aplicação dessa técnica na produção comercial de mudas implica elevados custos, que se devem, principalmente, ao funcionamento e à manutenção das salas de crescimento com regimes de luz artificial e temperatura controlada (KODYM \& ZAPATA-ARIAS, 1998), às perdas causadas pela contaminação in vitro, às desordens fisiológicas e morfológicas nas plantas e à baixa porcentagem de sobrevivência no estádio de aclimatização às condições ex vitro (KOZAI \& KUBOTA, 2001).

Em busca de alternativas para reduzir os custos da micropropagação convencional e melhorar a qualidade fisiológica das plantas produzidas, aumentando a sobrevivência durante o período de aclimatização, destaca-se o desenvolvimento da micropropagação fotoautotrófica. Esse processo consiste na produção de micropropágulos em meio de cultivo sem adição de sacarose no meio de cultura e sob condições ambientais que promovam a fotossíntese na planta com o uso de luz natural (KUBOTA \& TADOKORO, 1999). A micropropagação fotoautotrófica com o uso de luz natural permite a redução dos custos de produção de mudas diretamente, por meio da redução do gasto com energia elétrica, e indiretamente, por meio da melhoria da qualidade das mudas, reduzindo, tanto a perda de plantas durante a aclimatização, quanto à contaminação microbiana (ERIG \& SCHUCH, 2005). No entanto, para auxiliar o crescimento das plantas durante a micropropagação fotoautotrófica, é necessário aumentar a concentração de $\mathrm{CO}_{2}$ e reduzir a umidade relativa e a concentração de etileno nos frascos de cultivo (KOZAI \& KUBOTA, 2001; ARIGITA et al., 2002). Uma prática que vem sendo testada para favorecer as trocas gasosas é o uso de diferentes sistemas de vedação dos frascos, utilizandose materiais mais porosos, tais como algodão ou filtros permeáveis a gases (KOZAI \& NGUYEN, 2003).

Diante do exposto, este trabalho teve como objetivo avaliar a viabilidade técnica do enraizamento in vitro fotoautotrófico de mirtilo ( $\mathbf{V}$ ashei), cultivar 'Delite', comparando luminosidade, épocas, concentrações de sacarose e vedação dos frascos, visando reduzir os custos da micropropagação in vitro convencional e favorecer a produção de mudas dessa espécie.

\section{MATERIAL E MÉTODOS}

O experimento foi realizado no período de inverno (julho/agosto de 2006) e verão (dezembro/ janeiro de 2006-7), no Laboratório de Micropropagação de Plantas Frutíferas e na casa de vegetação pertencente ao Departamento de Fitotecnia, da Faculdade de Agronomia Eliseu Maciel (FAEM)/ Universidade Federal de Pelotas (UFPel), Pelotas, Rio Grande do Sul (RS). Como explantes, foram utilizados segmentos caulinares de mirtilo (Vaccinium ashei Reade), cultivar 'Delite', cultivados in vitro com seis gemas, ápice caulinar e folhas.

Para o enraizamento, os explantes foram cultivados em meio Wood Plant Media (WPM - LLOYD \& MCCOWN, 1980), adicionado de sacarose (conforme tratamento), mio-inositol (100 $\left.\mathrm{mg} \mathrm{L}^{-1}\right)$, ácido indolbutírico - AIB $\left(9 \mu \mathrm{M} \mathrm{L}^{-1}\right)$ e ágar $\left(6 \mathrm{~g} \mathrm{~L}^{-1}\right)$. O pH foi ajustado para 5,0 antes da adição do ágar. O meio de cultura distribuído em Erlenmeyers com capacidade de $250 \mathrm{~mL}$, contendo $50 \mathrm{~mL}$ de meio cada, foi autoclavado a $120^{\circ} \mathrm{C}$ e $1,5 \mathrm{~atm}$, por 20 minutos.

Os tratamentos consistiram de duas épocas do ano (inverno e verão), três concentrações de sacarose $\left(0 ; 15\right.$ e $\left.30 \mathrm{~g} \mathrm{~L}^{-1}\right)$, três tipos de vedação dos frascos (algodão, alumínio e filme plástico) e dois ambientes de cultivo: sala de crescimento ( 16 horas de fotoperíodo, densidade de fluxo de fótons no período de luz de $42 \mu \mathrm{mol} \mathrm{m} \mathrm{m}^{-2} \mathrm{~s}^{-1}$ ) e casa de vegetação (luz natural). A temperatura foi mantida a $25 \pm 2^{\circ} \mathrm{C} \mathrm{em}$ ambos os locais por meio do uso de condicionadores de ar.

O delineamento experimental foi inteiramente casualizado, fatorial $2 \times 3 \times 3 \times 2$, com quatro repetições por tratamento. Cada repetição constituiu-se de um frasco com cinco explantes.

Aos 60 dias de cultivo, foram avaliados a porcentagem de enraizamento, o número de raízes, o comprimento das raízes $(\mathrm{cm})$ e a massa fresca total $(\mathrm{mg})$. $\mathrm{O}$ número de raízes foi transformado em raiz quadrada $(X+0,5)$, e a porcentagem de enraizamento foi transformada em arcoseno raiz quadrada $(X / 100)$. Após a análise de variância, as médias foram comparadas 
pelo teste de Duncan (5\% de probabilidade de erro) e regressão polinomial, por do programa estatístico WINSTAT (MACHADO \& CONCEIÇÃO, 2005).

\section{RESULTADOS E DISCUSSÃO}

Em todos os tratamentos, as maiores porcentagens de enraizamento foram observadas em meio sem a adição de sacarose (Figura 1A e 1B). No entanto, a porcentagem de enraizamento é bastante influenciada pelas condições de cultivo, observandose, por meio da análise estatística, interação tripla entre a concentração de sacarose, o tipo de vedação dos frascos e a época do ano e entre o tipo de vedação dos frascos, a época do ano e o ambiente de cultivo. $\mathrm{Na}$ ausência de sacarose, durante o verão e em frascos vedados com algodão, o percentual de enraizamento foi superior a 90\% (Figura 1A). Esses resultados indicam que, para o enraizamento in vitro de mirtilo, não é necessário o uso de sacarose como principal fonte de energia. A eliminação da sacarose do meio de cultivo, além de reduzir os riscos de contaminação microbiana, também melhora as características fisiológicas das plântulas e facilita a aclimatização destas às condições ex vitro (AFREEN et al., 2002). Observou-se que o tipo de vedação dos frascos não alterou a porcentagem de enraizamento (Figura 1B) durante o verão e em condições de luminosidade controlada (sala de crescimento).

O número de raízes induzidas nos segmentos caulinares foi afetado pelos fatores testados. Obtendo-se interação significativa entre o tipo de vedação dos frascos, a época do ano e a concentração de sacarose (Figura 2A) e entre a concentração de sacarose, o ambiente de cultivo e a época do ano (Figura 2B). Durante o verão e na ausência de sacarose, o número de raízes foi aumentado com o uso de algodão na vedação dos frascos (Figura 2A), o que pode ser explicado pelo aumento da intensidade luminosa (maior fotoperíodo) quando comparado ao inverno, bem como pelo aumento das trocas gasosas com o uso de um sistema de vedação mais permeável a gases (no caso, o algodão), reduzindo a umidade relativa e o acúmulo de etileno nos frascos de cultivo. O fechamento dos frascos com filtros permeáveis a gases ou com chumaços de algodão favorece as trocas gasosas, aumentando a concentração de $\mathrm{CO}_{2} \mathrm{e}$, simultaneamente, reduzindo a umidade relativa e a concentração de etileno (KOZAI \& NGUYEN, 2003). O efeito benéfico da eliminação total ou parcial da sacarose no meio de cultura, sob condições de alta concentração de $\mathrm{CO}_{2}$ e alta luminosidade, juntamente com a redução da umidade relativa e da concentração de etileno nos frascos de cultivo, foi observado no processo de enraizamento de outras espécies (KANECHI et al., 1998; KOZAI \& KUBOTA, 2001; KODYM \& ZAPATA-ARIAS, 2001; ARIGITA et al., 2002).

Os explantes cultivados em meio livre de sacarose (Figura 2B) apresentaram maior número de raízes, principalmente quando associados ao cultivo em casa de vegetação sob luminosidade natural, ou seja, de forma fotoautotrófica. Com exceção dos explantes cultivados em $30 \mathrm{~g} \mathrm{~L}^{-1}$ de sacarose durante o verão e em casa de vegetação, a adição de sacarose causou um decréscimo linear no número e no comprimento das raízes, concomitante com o aumento da concentração. Esses resultados estão de concordo com os obtidos por KUBOTA \& TADOKORO (1999), os quais, comparando a micropropagação fotoautotrófica e fotomixotrófica em tomateiro (Lycopersicon esculentum Mill.), verificaram que explantes cultivados fotoautotroficamente
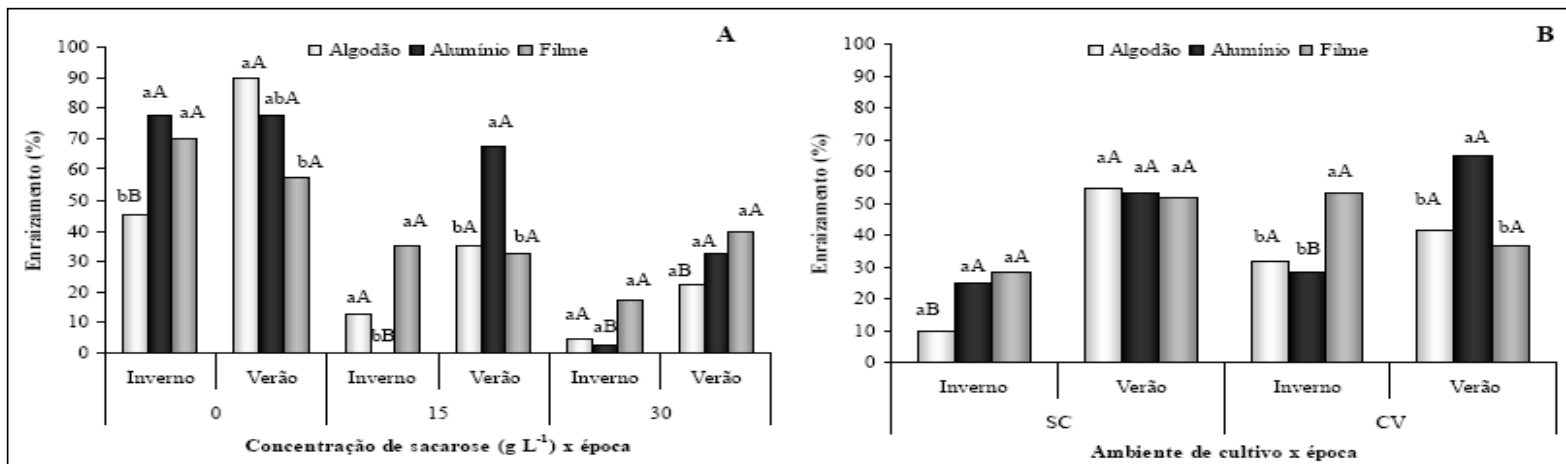

Figura 1 - (A) Efeito da concentração de sacarose, das épocas e da vedação dos frascos e (B) do ambiente de cultivo, da época do ano e da vedação dos frascos na porcentagem de enraizamento in vitro de mirtilo, cultivar 'Delite'. UFPEL, Pelotas-RS, 2007. As médias da figura A seguidas por letras distintas (minúsculas dentro da mesma época e concentração e maiúsculas dentro da mesma concentração e épocas distintas) e as médias da figura $\mathrm{B}$ (minúsculas dentro da mesma época e mesmo ambiente e maiúsculas comparando vedação dentro da época) diferem entre si pelo teste de Duncan a $5 \%$ de probabilidade de erro. $\mathrm{SC}=$ sala de crescimento e $\mathrm{CV}=$ casa de vegetação. 
Damiani \& Schuch.

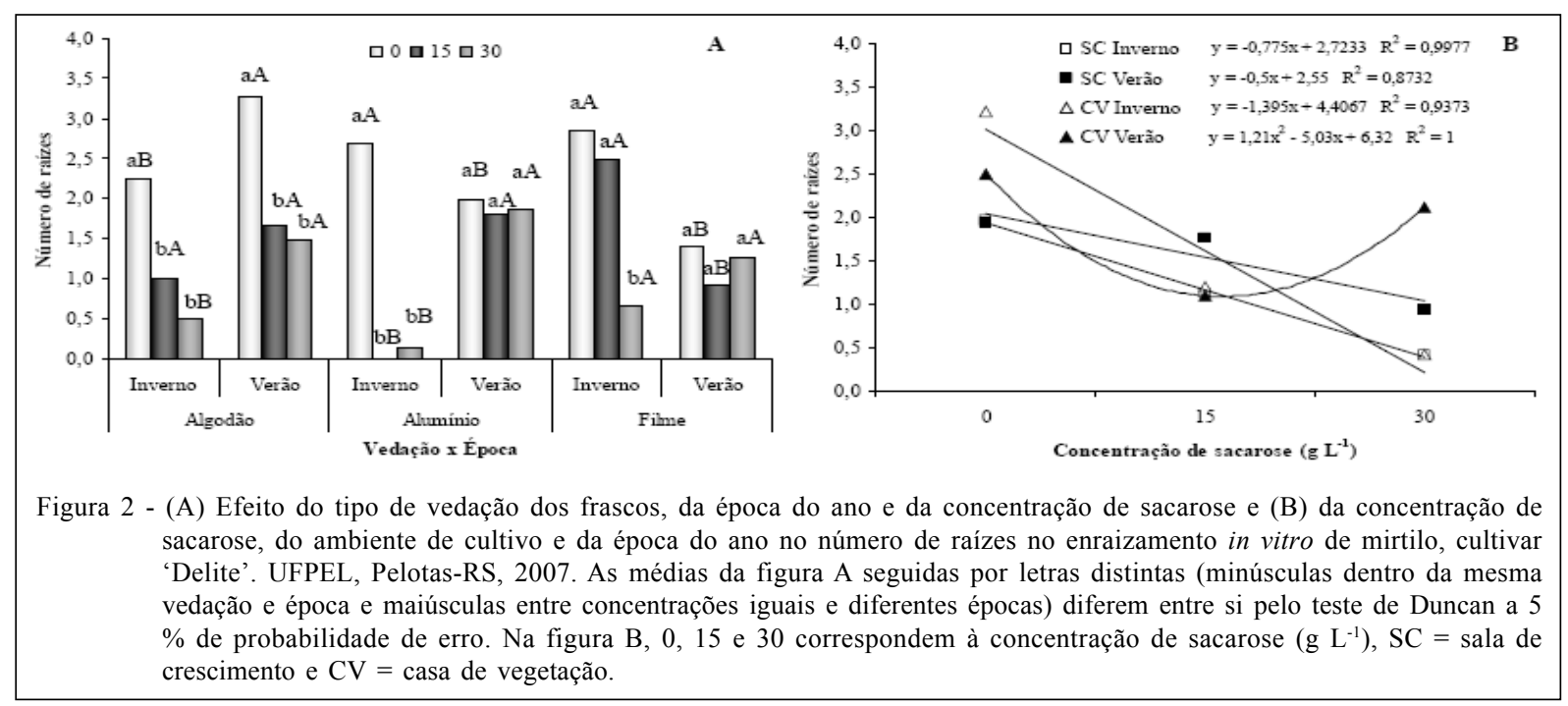

apresentavam maior vigor e maior desenvolvimento de folhas e raízes.

Com relação à variável comprimento de raiz (Figura 3A e 3B), observou-se que esta varia em função do tipo de vedação dos frascos e da época do ano, verificando-se um aumento do comprimento da raiz em frascos vedados com algodão e cultivados durante $\mathrm{o}$ verão (Figura 3A). O efeito positivo da vedação com algodão no comprimento das raízes foi aumentado com o cultivo em meio livre de sacarose (Figura 3B). O efeito da época do ano no crescimento radicular, além de apresentar uma relação estreita com o sistema de vedação dos frascos, apresentou uma interação significativa com a concentração de sacarose utilizada no meio de cultura (Figura 3B), verificando-se que o aumento de sacarose no meio de cultura durante o inverno causou um decréscimo linear do comprimento das raízes. REUTHER et al. (1992) estudaram o efeito de diferentes concentrações de sacarose no crescimento in vitro de Vitis vinifera da cultivar Riesling e, também, verificaram que o uso de baixas concentrações de sacarose $\left(5 \mathrm{~g} \mathrm{~L}^{-1}\right)$ e a ausência deste carboidrato favorecem o enraizamento e promovem o aumento do comprimento das raízes.

A interação entre a concentração de sacarose e o tipo de vedação dos frascos, a concentração de sacarose e o ambiente de cultivo, a época do ano e o tipo de vedação dos frascos e a época do ano e o ambiente de cultivo afetou o teor de massa fresca total (Figura 4A e 4B). Explantes
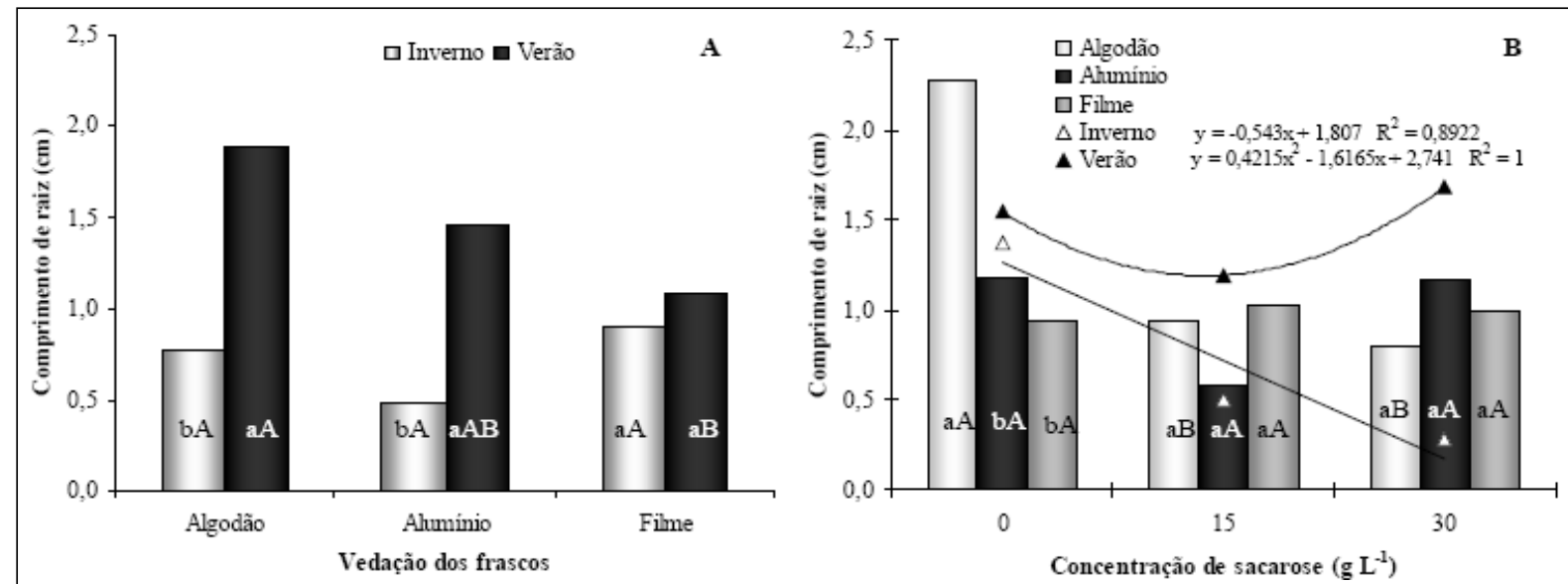

Figura 3 - (A) Efeito do tipo de vedação dos frascos e da época do ano (B), da concentração de sacarose, da época do ano e do tipo de vedação dos frascos no comprimento de raiz aos 60 dias de enraizamento in vitro de mirtilo da cultivar 'Delite'. UFPEL, Pelotas-RS, 2007. As médias da figura A seguidas por letras distintas (minúsculas dentro da mesma vedação e maiúsculas entre elas na mesma época) e as médias da figura B (minúsculas dentro da mesma concentração e maiúsculas entre elas na mesma vedação) diferem entre si pelo teste de Duncan a $5 \%$ de probabilidade de erro. 
Enraizamento in vitro de mirtilo em condições fotoautotróficas.

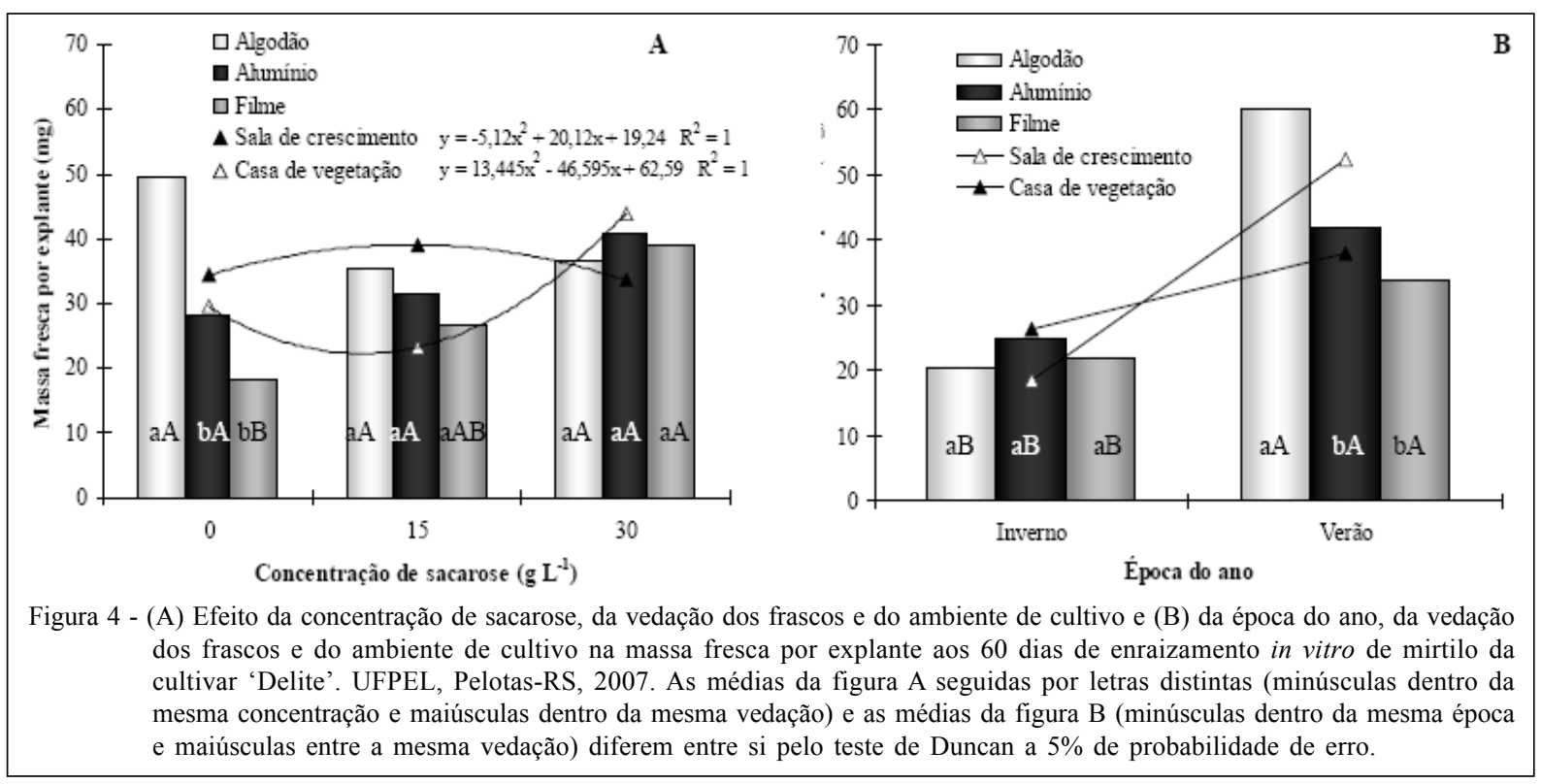

enraizados em meio livre de sacarose e em frascos vedados com algodão apresentaram um aumento significativo da massa fresca (Figura 4A). O sistema de vedação dos frascos, além de interferir na passagem de luz para o interior dos frascos, altera a interceptação de luz pelos explantes, sua capacidade de transpiração e, devido à retenção de água, a quantidade de matéria fresca (SOUZA et al., 1999). Porém, quando cultivados em meio contendo sacarose, o fechamento dos frascos com algodão não difere dos demais, exceto para filme plástico na concentração de $15 \mathrm{~g} \mathrm{~L}^{-1}$. Quanto ao ambiente de cultivo e à concentração de sacarose (Figura 4A), observou-se que explantes cultivados em sala de crescimento não diferem estatisticamente quanto à presença ou ausência de sacarose. No entanto, quando cultivados em casa de vegetação, o cultivo em meio contendo $30 \mathrm{~g} \mathrm{~L}^{-1}$ de sacarose aumentou significativamente a quantidade de massa fresca. $\mathrm{O}$ enraizamento durante o verão (Figura 4B) favoreceu o aumento da matéria fresca em ambos os locais de cultivo, mas principalmente quando associados ao cultivo em frascos vedados com algodão. $\mathrm{O}$ aumento da massa fresca durante o verão, associado ao fechamento dos frascos com algodão, pode ser explicado pelo aumento das taxas fotossintéticas em virtude do aumento do fotoperíodo em comparação ao inverno e pela maior permeabilidade do algodão, quando comparado ao alumínio e filme plástico, aumentando as trocas gasosas. Na ausência de sacarose, o enriquecimento do meio com $\mathrm{CO}_{2}$ e o aumento da intensidade luminosa são fundamentais para o aumento da taxa fotossintética e, conseqüentemente, da quantidade de massa fresca e seca (KOZAI \& KUBOTA, 2001),

\section{CONCLUSÃO}

O enraizamento fotoautotrófico de mirtilo realizado por meio do cultivo em meio livre de sacarose aumenta o percentual de enraizamento e o número de raízes e, quando associado à vedação dos frascos com algodão, promove, também, o aumento do comprimento das raízes e da massa fresca total. Durante o verão são obtidos os maiores percentuais de enraizamento e este pode ser realizado com sucesso em casa de vegetação.

\section{AGRADECIMENTOS}

Este trabalho foi desenvolvido com o apoio do Ministério da Ciência e Tecnologia (MCT), do Conselho Nacional de Desenvolvimento Científico e Tecnológico (CNPq) e da Fundação de Amparo à Pesquisa do Estado do Rio Grande do Sul (FAPERGS).

\section{REFERÊNCIAS}

AFREEN, F. et al. Photoautotrophic culture of Coffea arabusta somatic embryos: photosynthetic ability and growth of different stage embryos. Annals of Botany, London, v.90, p.11-19, 2002. Disponível em: http://aob.oxfordjournals.org/cgi/content/ full/90/1/11\#MCF150F1. Doi: 10.1093/aob/mcf151.

ARIGITA, L. et al. Influence of $\mathrm{CO}_{2}$ and sucrose on photosynthesis and transpiration of Actinidia deliciosa explants cultured in vitro. Physiologia Plantarum, Copenhagen, v.115, n.1, p.166-173, 2002. Disponível em: http://www3.interscience.wiley.com/journal/118911524/ abstract?CRETRY=1\&SRETRY=0. Doi: 10.1034/j.13993054.2002.1150119.x.

CASTILlO, A. et al. Investigación en arandanos en Uruguay: propagación in vitro y evaluación de variedades por INIA. In: 
SIMPÓSIO NACIONAL DO MORANGO, 2.; ENCONTRO DE PEQUENAS FRUTAS E FRUTAS NATIVAS, 2004, Pelotas, RS. Palestras e Resumos... Pelotas: Embrapa Clima Temperado, 2004. p.225-228. (Documentos 124).

ERIG, A.C.; SCHUCH, M.W. Micropropagação fotoautotrófica e uso da luz natural. Ciência Rural, Santa Maria, v.35, n.4, p.961-965, 2005. Disponível em: http://www.scielo.br/ s c i e lo.php?s cript=sci_art text \& pid = S 0103 84782005000400039. Doi: 10.1590/S010384782005000400039 .

FACHINELlO, J.C. et al. Propagação de plantas frutíferas de clima temperado. 2.ed. Pelotas: UFPel, 1995. 179p.

GRATTAPAGLIA, D.; MACHADO, M.A. Micropropagação. In: TORRES, A.C. et al. Cultura de tecidos e transformação genética de plantas. Brasília: Embrapa-SPI / Embrapa-CNPH, 1998. V.1, p.183-260.

KANECHI, M. et al. The effects of carbon dioxide enrichment, natural ventilation, and light intensity on growth, photosynthesis, and transpiration of cauliflower plantlets cultured in vitro photoautotrophically and photomixotrophically. Journal of the American Society for Horticultural Science, Mount Vernon, v.123, n.2, p.176$181,1998$.

KODYM, A.; ZAPATA-ARIAS, F.J. Low-cost alternatives for the micropropagation of banana. Plant Cell, Tissue and Organ Culture, Hague, v.66, n.1, p.67-71, 2001. Disponível em: www.ingentaconnect.com/content/klu/ticu/2001/00000066/ 00000001/00335296. doi: 10.1023/A:1010661521438.

KODYM, A.; ZAPATA-ARIAS, F.J. Natural light as an alternative light source for the in vitro culture of banana (Musa acuminata cv. 'Grand Naine'). Plant Cell, Tissue and Organ Culture, Hague, v.55, n.2 p.141-145, 1998. Disponível em: http://www.ingentaconnect.com/content/klu/ticu/1998/ 00000055/00000002/00200762. Doi: 13990j3474114124/ 10.1023/A:1006119114107.

KOZAI, T.; NGUYEN, Q.T. Photoautotrophic micropropagation of woody and tropical plants. In: JAIN, S.M.;
ISHII, K. Micropropagation of woody trees and fruits. Dordrecht: Kluwer Academic Publishers, 2003. p.757-781.

KOZAI, T; KUBOTA, C. Developing a photoautotrophic micropropagation system for woody plants. Journal of Plant Research, Tokyo, v.114, n.4, p.525-537, 2001. Disponível em: www.springerlink.com/index/9FQGYVYPVHQMBC1D.pdf. Doi: $10.1007 /$ PL00014020.

KUBOTA, C; TADOKORO, N. Control of microbial contamination for large-scale photoautotrophic micropropagation. In vitro. Cellular and Developmental Biology-Plant, New York, v.35, n.4, p.296-298, 1999. Disponível em: www.springerlink.com/index/9716R4GK3641U375.pdf. Doi: 10.1007/s1 1627-999-0037-6.

LLOYD, G.; McCOWN, B. Commercially feasible micropropagation of mountain laurel (Kalmia latifolia) by use of shoot-tip culture. Proceedings of the International Plant Propagation Society, Seattle, v.30, p.421-427, 1980.

MACHADO, A.A.; CONCEIÇÃO, A.R. WinStat - sistema de análise estatística para Windows. Versão Beta. Pelotas: Universidade Federal de Pelotas, 2005. (Software).

MADAIL, J.C.M.; SANTOS, A.M. Aspectos econômicos. A cultura do mirtilo. Pelotas: Embrapa Clima temperado, 2004. p.63-68. (Documentos, 121).

REUTHER, G. et al. Influence of nutricional and environmental factors on productivity and photoautotrophy of transplants in vitro. Acta Horticulturae, Yokohama, n.319, p.47-52, 1992.

SOUZA, C.M. De et al. Influência dos fatores físicos na regeneração de brotos em repolho. Ciência e Agrotenologia, Lavras, v.23, n.4, p.830-835, 1999.

TREVISAN, R. et al. Enraizamento de estacas herbáceas de mirtilo: influência da lesão na base e do ácido indolbutírico. Ciência e Agrotecnologia, Lavras, v.32, n.2, p.402-406, 2008. Disponível em: www.scielo.br/scielo.php?pid=S1413$70542008000200009 \&$ script $=$ sci_arttext. Doi: 10.1590/ S1413-70542008000200009. 